\title{
METÁFORA VEGETAL Y MÍSTICA DE LA MATERIA EN EL POEMARIO GUITARRA NEGRA: UNA APROXIMACIÓN A LA POESÍA DE LUIS ALBERTO SPINETTA ${ }^{1}$
}

\author{
Gabriel Meza Alegría \\ Universidad de Concepción, Concepción, Chile \\ gmeza@udec.cl
}

\section{RESUMEN / ABSTRACT}

En este artículo se presenta un estudio del poemario Guitarra negra (1978) del músico Luis Alberto Spinetta, donde se entregan algunas reflexiones generales en torno a su incursión en el ámbito poético y a su situación en la tradición literaria argentina. El análisis se centra en examinar algunos conceptos fundamentales para concebir una poética del autor, específicamente, las nociones de metáfora vegetal y mística de la materia. Dichos conceptos permiten proponer que la revelación de lo sagrado es el elemento esencial en la poesía del argentino. Además, en función de esta premisa, se establecen relaciones entre su práctica poética con el concepto de postontología propuesto por Wolfgang Janke (1995), en sus planteamientos sobre ontología y postmodernidad.

Palabras Clave: Luis Alberto Spinetta, poesía, música, espiritualidad, mística.

1 Este artículo surge de uno de los capítulos de la tesis doctoral "Julio Cortázar, Mario de Andrade, Pedro Aznar y Luis Alberto Spinetta: cuatro propuestas sobre relaciones y desplazamientos entre literatura y música en el contexto de la postmodernidad", con el cual su autor obtuvo el grado de Doctor en Literatura Latinoamericana en la Universidad de Concepción, Chile. Año 2016. Además, una versión preliminar de este estudio fue leída en Santiago el 27 de octubre de 2016, bajo el título "Metáfora vegetal y mística de la materia en Guitarra negra de Luis Alberto Spinetta: registro de una postontología músico-poética", en el XX Congreso Internacional de la Sociedad Chilena de Estudios Literarios, SOCHEL 2016. Realizado en la Facultad de Filosofía y Humanidades de la Universidad de Chile, entre los días 25 y 28 de octubre de 2016. 
Vegetable and Mystic Metaphor of Matter in the Poem Collection Guitarra NEgra: An ApProach to the PoEtry of LUIS ALBERTo SPINETTA

This article presents a study of the poetry book Guitarra negra (1978) by the Argentinian musician Luis Alberto Spinetta, where some general thoughts are expressed about his incursion into the poetic environment and his situation in the Argentinian literary tradition. The analysis focuses on examining some fundamental concepts to conceive a poetic of the author, specifically, the notions of vegetable and mystic metaphor of matter. These concepts allow the argument that the revelation of the sacred is the essential element in Spinetta's poetry. Moreover, following this premise, relations are established between his poetic practice and the concept of Postontology proposed by Wolfgang Janke (1995), in his approaches to ontology and postmodernism.

KEYWORDS: Luis Alberto Spinetta, poetry, music, spirituality, mysticism.

Recepción: 28/04/2017

Aprobación: 13/07/2017

\section{LUIS ALBERTO SPINETTA: CONSIDERACIONES GENERALES SOBRE SU PRÁCTICA MUSICAL Y LITERARIA}

Luis Alberto Spinetta (1950-2012) es uno de los exponentes más reconocidos de la tradición del rock argentino y uno de los músicos más respetados y admirados de su generación y de la música popular latinoamericana contemporánea. Además de una vasta producción como solista, integró las bandas "Almendra", "Pescado Rabioso", "Invisible", "Spinetta Jade" y "Spinetta y los Socios del Desierto". En su producción musical, uno de los aspectos que más destaca es la capacidad poética presente en las letras de sus canciones, una sutileza léxica y sintáctica unida a una profundidad semántica singularizan su música y estos elementos le confieren un espesor poético que sobresale dentro del marco referencial de la letra de canción. Esta singularidad en la música de Spinetta se conecta con otra faceta artística del autor y de la cual poco se ha dicho en términos críticos relevantes para su estudio, me refiero a su condición de poeta. En 1978, Luis Alberto Spinetta publica Guitarra negra, su única obra poética donde están contenidas gran parte de las ideas estéticas que cruzan su obra musical, y donde se perfila una poesía que puede ser estudiada de manera independiente de sus letras de canciones, pues a pesar de los vínculos temáticos que surgen entre ambas escrituras, su poesía ostenta plena autonomía en relación con sus letras al ser textos que no dependen de un contexto musical específico ni completan su 
sentido en una sonoridad instrumental; no obstante, existe un vacío crítico en torno a ella, pues su estudio no ha cruzado con plenitud las fronteras de los medios de prensa especializados en música o de las publicaciones de carácter biografista. No se observan aún estudios críticos desde el ámbito literario que instalen a Guitarra Negra en algún momento de la tradición literaria argentina o que hayan delimitado la poética del autor. Como referencias previas se encuentra el texto "Luis Alberto Spinetta: la música de las esferas", de Belén Iannuzzi, incluido en el libro Poéticas del rock, Volumen I (2007), editado por Oscar Conde, que aborda el valor poético de la letrística de Spinetta; y son de gran valor los estudios del académico argentino Jorge Monteleone en cuanto a la influencia de la literatura en la música de Spinetta y al contexto del rock argentino en el cual se desarrolla su obra, dentro de los cuales destaca el artículo "Spinetta/Artaud. Verano del setenta y tres", publicado en Controversias de lo moderno: la secularización en la historia cultural latinoamericana (2010), editado por Enrique Foffani. Además de las fuentes biográficas fundamentales para el estudio de la obra del músico como: Spinetta: crónica e iluminaciones (1988) de Eduardo Berti y Martropía. Conversaciones con Spinetta (2006) de Juan Carlos Diez.

En cuanto a estudios que aborden de manera específica el poemario Guitarra Negra, destaca el artículo "Arremete viajero" de Jorge Hardmeier publicado en el número 12 de la revista de arte, literatura y pensamiento Boca de Sapo (2012), que recorre el poemario en función de la letrística de Spinetta entregando significativas claves de lectura en torno a la textualización de la figura de Dios, el alma y el cuerpo, el símbolo del viaje, el ciclo de la muerte y el renacimiento, la revelación de lo sagrado en la naturaleza y la función de la palabra y la poesía en la experiencia de los hablantes. Por último, cabe destacar, además, el estudio "Guitarra negra, palabras luminosas" de Sandra Gasparini, incluido en el libro Iniciado del alba. Seis ensayos y un epílogo sobre Luis Alberto Spinetta (2015), editado por la propia Gasparini, que aborda, principalmente, las huellas surrealistas en la poesía de Spinetta. Según la misma autora explica, su trabajo se centró en “[p]ensar qué genealogías tiene ese poemario [...] desde ya el surrealismo, por supuesto, pero es una apropiación muy personal que hace Spinetta del surrealismo, entonces ver qué conexiones tiene con esa estética, cómo eso abreva en la letrística anterior y en la posterior" (Entrevista radial en Verano Fatal 2017).

Para iniciar este estudio se puede indicar que en la obra creativa de Spinetta se observan ciertas recurrencias temáticas entre su poesía y las letras de sus canciones, aunque para su análisis es preciso respetar las distinciones entre 
ambas escrituras, principalmente, porque la letra de canción es un texto que en su génesis está sujeto a una estructura rítmico-melódica que la determina. Al respecto, Jorge Monteleone indica: "Combinada con la música y el canto, en la letra de rock, el ritmo no está representado por el acento o la rima del poema, sino por el golpe (beat) y su expansión periódica en las bases rítmicas" (Rock, párr. 5). Y, posteriormente, especifica el vínculo entre letra de rock y poesía: "Aunque la letra de rock no es literatura, su efecto es, sin embargo, poético" (Rock, párr. 5). Para el estudioso, la letra de canción no depende de una naturaleza poética sino rítmica, pues el carácter poético del texto se expande a través del ritmo hacia lo corpóreo funcionando como una expansión del sentido poético:

El rock produce un tipo de subjetividad que la literatura no agota: la prolonga y modifica. De allí que leer la letra de rock como un poema minusválido es una simplificación. Todo el cuerpo, como figura imaginaria, está comprometido en su realización extática. Allí donde la palabra ritma, el rock finaliza en un cuerpo que le da su acento silábico (Figuras, párr. 2).

Monteleone se refiere a la letra de canción, específicamente dentro del marco de la tradición del rock, entendiendo éste como un sistema completo que integra una forma de ejecución musical definida y una representación estética que abarca el pensamiento y la conducta de músicos y oyentes, hecho que define como cultura o pasión rocker. Lo más significativo para el autor es el carácter corpóreo que lo define: "El rock es una forma artística que pone el ritmo y las cargas de energía corporal en el centro de una significación nueva. Aquello que Barthes llamó significancia: el sentido en cuanto es producido sensualmente" (Rock, párr. 4). Y, posteriormente, establece una similitud con la poesía: "En el poema, ese elemento de ruptura está dado por los efectos musicales del lenguaje, las repeticiones, los juegos rítmicos, el sin-sentido, la alteración de la sintaxis, los neologismos, etc.” (Rock, párr. 4).

Desde la perspectiva de Monteleone, el rock y la poesía están estrechamente vinculados. El ritmo vendría a ser el elemento primordial de esta vinculación, aunque para el estudioso, en el rock el ritmo deriva en una manifestación corporal que lo define, mientras que en la poesía el ritmo se encuentra sugerido por procedimientos literarios como la sintaxis poética. Esta perspectiva permite entender que la letra de canción añade significaciones sensibles y musicales que implican un análisis propio independiente del análisis poético tradicional, pues el cómo se canta un verso, la intención emotiva de la voz, 
la tonalidad, la nota musical específica que contiene cada una de sus partes constituyen elementos fundamentales a considerar al momento de acercarse a un análisis crítico, lo que deja en claro la necesidad de incorporar la audición como aproximación primordial al texto.

En relación con la obra artística de Luis Alberto Spinetta, se puede indicar que el vínculo entre rock y poesía es evidente, en primer término, por el carácter poético que la prensa musical y las publicaciones biografistas le han asignado a Spinetta como músico, segundo, por las influencias literarias que se hallan manifiestas en su obra musical, situación que tiene su máxima expresión en el disco Artaud de 1973, dedicado al poeta francés, y, en tercer término, por la relación temática que se observa entre su poesía formal cifrada en Guitarra negra y las letras de sus canciones. Esta situación lleva a la interrogante "¿por qué un letrista de la complejidad y originalidad spinettianas dividió sus composiciones verbales en canciones por un lado y poemas por otro?" (Gasparini, Guitarra 90). Es posible vislumbrar una respuesta en que las variadas influencias literarias y teóricas con las que Spinetta tomó contacto hayan sugerido límites entre su letrística y su poesía, en cuanto a la profundidad en el desarrollo textual que cada tipo de escritura ofrece.

En las conversaciones con Juan Carlos Diez (2006), el mismo Spinetta refiere su afición a la escritura desde su adolescencia, además de la afición a escribir de su padre: "mi viejo empezó a escribir poesía hace unos treinta años. Por ahí escribía antes de que yo empezara [...] es un poeta muy sensible, con un lenguaje muy llamativo y profundo" (177). En el mismo texto, Spinetta expone su interés por la literatura de Carlos Castaneda, por las teorías de Foucault y George Bataille, por la obra de Antonin Artaud, René Daumal, Rimbaud, Baudelaire, Cocteau, Lautréamont, y se refiere a autores como Sade, Kafka, Blake y Brontë, por lo tanto, Spinetta se muestra como un lector instruido en términos literarios, hecho que influiría en su propia poesía a pesar de la humildad que manifiesta al referirse a su propia praxis escritural: "la escritura es muy grande y hay escritores gigantes. Yo asumo eso desde una posición muy humilde. Hablo de los sentimientos que me ocurren a mí y no lo hago como si fuera un erudito en poesía, o alguien que realmente merece que le presten atención, porque no me he dedicado especialmente a escribir" (375-376). Destaca en esta observación del músico la mención a los sentimientos como pilar fundamental de su poesía, pues podría estar influida por sus lecturas de los poetas decimonónicos como Blake y Lautréamont, entregándonos la posibilidad de rastrear algunas concepciones neorrománticas en su escritura, las cuales convivirían con las 
influencias surrealistas provenientes del contacto de su obra con la figura de Antonin Artaud.

En 1973, Spinetta graba el disco dedicado al poeta francés en el cual desarrolla las impresiones causadas por su obra, una manera de conjurar el impacto surgido en el momento de tomar contacto con ella, que se trasformó en uno de los discos clásicos de la tradición del rock argentino, respecto de la composición del disco Spinetta explica:

El disco tiene algo de antídoto. Una vez más, creo que yo traté de asirme a las formas poéticas y al impulso que guiaba al autor más que al acontecimiento que él describe. No me interesa mucho el dolor, sino la forma en que uno puede llegar tan profundamente dentro de sí mismo como para encontrarlo de esa manera, que es lo que hizo Artaud. Por lo tanto no me gusta mucho el producto de todo eso, que es el sufrimiento y cómo verlo dentro de uno. Pero sí el hecho de haber corrido el riesgo de escribir increíblemente eso (Diez 290).

Cabe destacar, además, que la singularidad de la obra de Antonin Artaud no solamente está reflejada en las ideas presentes en las canciones del disco de Spinetta, sino también en el disco como objeto: "La tapa de Artaud no sólo excedía el tamaño normal, sino que se extendía en una forma de ángulos y líneas curvas, como una especie de paralelepípedo, que quizás evocaba la figura algo abstracta de un pez" (Monteleone, Spinetta 2-3). Y también en la interpretación musical; de ahí que Jorge Monteleone indique: "Hablar de Artaud supone, en un mismo acto, escuchar Artaud" (Spinetta 5).

\section{SITUACIÓN DE SPINETTA EN LA TRADICIÓN LITERARIA ARGENTINA}

Habiendo revisado algunas influencias literarias de importancia en la obra creativa de Luis Alberto Spinetta, cabe precisar si es posible ubicarlo en algún punto de la tradición literaria argentina. Una periodización general sobre la literatura latinoamericana la entrega Juan Carlos Ghiano, quien indica: "La literatura de América hispánica puede dividirse en dos grandes épocas: la que corresponde a la literatura política de la Independencia y la Organización y la que corresponde a las obras más o menos desinteresadas de los años siguientes" (153). Posteriormente, aplica esta división al contexto literario argentino: 
Ambos sectores se distinguen con relativa nitidez en la Argentina. Para el primero -nuestro siglo XIX- el signo decisivo corresponde al Romanticismo social, con predominio casi excluyente de la influencia francesa; para el segundo -nuestro siglo XX- el signo fundamental corresponde al Modernismo, comprendido como síntesis de influencias diversas, donde todavía es fundamental, aunque no exclusiva, la francesa (153).

Dentro del marco de la poesía argentina del siglo XX, Ghiano establece tres épocas sucesivas y coexistentes. La primera, formada en el modernismo y que profundiza en algunos aspectos de dicho movimiento, donde se encontrarían figuras como Alfonsina Storni; la segunda, una generación de poetas que habría reaccionado contra el paradigma poético de Leopoldo Lugones, el cual, según el autor, manifestaba un escaso lirismo; esta generación habría postulado una lírica profundización de las metáforas y una intencionada ampliación de los temas. En este grupo el autor sitúa a figuras como Borges y Girondo; y por último, una tercera etapa que propone una nueva reacción que implica una renovación en sencillez y la búsqueda de la esencialidad poemática, donde figuran autores como Vicente Barbieri.

Considerando periodizaciones aún más específicas, es posible citar la generación del 60 que precede al momento de producción poética de Spinetta, la que bajo algunas perspectivas "se aunó en una denuncia de un orden que se quebraba, en el cuestionamiento de formas poéticas que consideraban gastadas y en la profunda aspiración de una utopía en donde la Belleza, la Justicia y la Verdad pudieran realizarse" (Vázquez y Kuperman 217). Por otra parte, algunas perspectivas teóricas han observado en esta generación un carácter ecléctico a nivel de discursos que se configura como rasgo distintivo: "la mezcla de discursos literarios de otro orden (narrativo), y de discursos no literarios (informativo, científico, coloquial) con el discurso poético, es el rasgo más importante de la poética del 60. El texto se plantea como una instancia de encuentro de otros textos sociales" (Porrúa 116).

En este contexto, no podemos olvidar el desarrollo del surrealismo en Argentina, debido a la asociación que suele establecerse entre esta corriente y la obra de Spinetta en base a la creación del disco Artaud. Kira Poblete establece que la praxis surrealista argentina tiene tres períodos: uno de iniciación y búsqueda comprendido entre 1928 y 1949, uno de cristalización y auge entre 1950 y 1957, y un último período de evolución y transformación comprendido entre los años 1958 y 1973, el que coincide con la fecha de lanzamiento del disco de Spinetta. Según Poblete, los escritores surrealistas 
en la Argentina "además de buscar la modificación del espíritu del individuo, promovían un cambio de vida, el cambio de la sociedad, cuyos valores e instituciones cuestionaban" (95).

Por último, en un estudio sobre las revistas literarias rosarinas se configura una generación comprendida entre 1965 y 1976, importante de destacar por la alusión directa a Luis Alberto Spinetta como parte de los músicos que ayudaron a construir esta nueva identidad, y por la descripción del clima ideológico y el contexto social de la época:

Esta generación se encuentra inmersa en un mundo donde las ideologías imperantes comenzaban a desmoronarse: Surgían los llamados "hippies" pacifistas como reacción a la aniquilación que se estaba produciendo en la guerra que EE.UU. había creado en Vietnam. Latinoamérica optaba por permanecer en una actitud pacifista. En la Argentina, la juventud se plegaba a la misma defensa de los "hippies". Existía una confluencia ideológica entre los izquierdistas y los "pelos largos" del momento: las dos tendencias estaban en contra de la guerra aunque de diferente manera. Se postulaban contra el gobierno de Onganía, la proscripción y se encontraban al margen de las instituciones. Acorde a sus necesidades nace para esta generación un nuevo lenguaje donde se reflejaba su propia identidad. Músicos del rock como Spinetta, Lito Nebbia, el grupo Sui Generis, son claros exponentes de esa realidad (Minniti et al. 10).

Estos períodos literarios permiten entender el contexto sociopolítico, cultural y estético anterior a la obra de Spinetta, como también el momento en que el argentino inicia su producción desde lo musical a lo literario. Lo musical en 1969 con el primer disco de "Almendra" y, posteriormente, llegando a Artaud en 1973, disco que genera un puente entre música y literatura en la producción del autor, para luego desarrollar su obra poética en 1978 con la publicación de Guitarra negra. Cabe destacar que estos momentos y generaciones son solo un marco referencial para la producción poética de Spinetta y no constituyen una adhesión estricta a la tradición literaria, pues una periodización que favoreciera la inclusión de Spinetta al canon literario tendría que superar "el desamparo histórico [y crítico] en que se encuentran las literaturas no ortodoxas" (Iniesta 193). Además, desde la distinción entre "periodización cíclica" y "periodización evolutiva" propuesta por Gaspar Pio del Corro (1989), donde cíclica es "la periodización que atiende preferentemente a las ondas de influencia estético-literaria que se suceden 
sobre nosotros, en movimiento horizontal, es decir, procedentes de vertiente exógena-casi siempre Europa y Norteamérica" (191), y evolutiva es "la que se hace atendiendo con preferencia al movimiento endógeno de la creatividad, movimiento vertical, de abajo hacia arriba, procedente desde el seno de la propia comunidad" (191), se puede plantear que la segunda tendría mejor correspondencia con la obra de Spinetta. Esto debido a que es una literatura subyacente originada en un acervo popular y masivo (rock), en distinción a la literatura ortodoxa que se regiría por las formas tradicionales de periodización que se corresponden con la propuesta cíclica.

\section{GUITARRA NEGRA: CLAVES PARA UNA POÉTICA DEL AUTOR}

Guitarra negra tuvo su primera edición a cargo de Ediciones Tres Tiempos en 1978 en la ciudad de Buenos Aires. El poemario recoge cerca de setenta textos divididos en siete secciones. No se observa en los poemas el uso de estructuras tradicionales en estrofa, verso ni rima, su escritura se basa íntegramente en el verso libre y las temáticas varían desde reflexiones subjetivas a descripciones del mundo físico. En el conjunto de textos reunidos en este libro, más de la mitad de ellos son intitulados, hecho que podría guardar relación con la nota inicial del autor donde señala: "propongo que se olvide cada palabra a medida que ella se lea" (13). Postura subversiva frente al procedimiento literario tradicional, pues de esta reflexión se infiere una concepción de la práctica escritural donde la experiencia instantánea y la contemplación se muestran como lo más significativo, y no la posibilidad de registrar o configurar una poética desde la perspectiva del canon, hecho que podría haber determinado el que Spinetta nunca más volviera a publicar posteriormente. Sin embargo, a pesar de esta instantaneidad, existen en Guitarra negra algunos ejes temáticos que aparecen como constantes que determinan el conjunto de textos; estos son: 1) las reflexiones en torno al lenguaje poético y la condición de artista, 2) la manifestación de una imaginería mítica a través de la mención a seres sobrenaturales, 3) la conciencia de los hablantes líricos de una realidad metafísica anterior a la existencia material del sujeto, y 4) la mención a la naturaleza y a sus componentes, cargados de un elemento sagrado y trascendente. Este último elemento en el poemario es desarrollado mediante una especial relación simbólica entre lo sagrado y el reino vegetal que es 
posible entender como una metáfora vegetal ${ }^{2}$ que singulariza la obra poética de Spinetta. Cabe destacar que este especial vínculo con la naturaleza sobrepasa los límites de Guitarra negra, pues es uno de los tópicos más recurrentes en las letras de sus canciones y uno de los recursos textuales que le ha dado carácter de poeta en lo musical dentro del rock argentino, canciones como "Todas las hojas son del viento" (Artaud, 1973), "Cisne" (Para los árboles, 2003), "Durazno sangrando" (Durazno sangrando, 1975) o "Barro tal vez" (Kamikaze, 1982), son representativas de esta situación.

Para una mayor comprensión de la idea de metáfora vegetal y de la singular noción de espiritualidad en la obra de Spinetta, he recurrido al concepto de mística de la materia que algunos estudios refieren, principalmente, en alusión a las poesías de Pablo Neruda y Gabriela Mistral. Sin embargo, es preciso hacer antes algunas observaciones conceptuales al respecto sobre las nociones de trascendencia y mística utilizadas en este estudio.

En cuanto a la idea de trascendencia, la estudiosa Cecilia Rubio (2007) la define como "un movimiento del espíritu hacia aquello que excede los límites de nuestra existencia inmanente" (313). Definición que permite asociar el concepto con la espiritualidad y lo sagrado, y que resulta más abarcadora que la presentada por diccionarios filosóficos como el de José Ferrater Mora, donde el concepto es entendido como "estar más allá" de algo, "sobre-salir" o "sobre-pasar" un límite (828-829).

Ahora bien, ¿qué es eso que excede los límites de nuestra existencia inmanente?; pareciera ser que una dimensión más allá de tiempo, espacio y razón, que se caracteriza por lo inefable y misterioso, y que contiene la grandeza de lo sagrado, tal como figura en el concepto de lo "numinoso" propuesto por Rudolf Otto (1965), donde es definido como el aspecto irracional contenido en la cualidad de santo: "entre sus diversos componentes [lo santo] contiene un elemento específico, singular, que se sustrae a la razón [...] y que es árreton, inefable; es decir, completamente inaccesible a la

2 La expresión "metáfora vegetal" la he recogido de los comentarios sobre Guitarra negra de Jorge Hardmeier, quien en su artículo "Arremete viajero" (2012) publicado en Boca de sapo $\mathrm{N}^{\circ} 12$, se refiere a la relación de la poesía de Spinetta con el mundo vegetal mediante expresiones como: "simbolismo de las plantas" (71) y "metáfora de las plantas" (71). Además, en una versión anterior del mismo escrito en una nota de weblog de la Biblioteca AUPA, Hardmeier especifica: “Guitarra negra', gran metáfora vegetal. No es extraña la imagen, en un artista como Luis Alberto Spinetta. Las letras de sus canciones han abordado, varias veces, el simbolismo de las plantas" (párr. 6). 
comprensión por conceptos" (16). O como lo definiera Maurice Blanchot (1969) mediante el concepto de la noche, espacio más allá de lo inmanente donde habita lo misterioso y trascendente, espacio en el cual todo desaparece, donde se aproximan la ausencia, el silencio y el reposo. Para Blanchot, esta noche es el afuera, la otredad, pues nunca se puede ingresar en ella, solo es posible a través de ella alcanzar lo otro: "La noche es inaccesible porque tener acceso a ella es acceder al afuera, es permanecer fuera de ella y perder para siempre la posibilidad de salir de ella" (154). Estos planteamientos de Otto y Blanchot permiten explicar esa dimensión más allá de lo inmanente a la cual tiende el espíritu y que en este estudio se sugiere está presente en la poesía de Luis Alberto Spinetta.

En cuanto al concepto de mística, el académico Marcelo Garrido (2010) entrega una definición que destaca por su claridad:

A la mística corresponde la mayor intensificación de lo religioso. No es la mística lo propiamente religioso sino más bien lo religioso intensificado. La subjetividad mística es actuante de su propia religiosidad y como tal su necesidad de comunión aspira a grados de intensificación progresiva, a una incorporación definitiva y absoluta de su ser escindido con la unidad absoluta de la supra-presencia (179).

La mística, entonces, es una experiencia de intensificación de lo religioso, experiencia que es progresiva y que comúnmente ha sido descrita en función de un proceso iniciático, en el cual se van superando distintas etapas con el fin de alcanzar una experiencia y un conocimiento trascendentes, que permiten, a su vez, la unión con la divinidad o lo sagrado como estado final. $\mathrm{Al}$ respecto, Garrido, siguiendo los planteamientos de San Juan de la Cruz ${ }^{3}$ entrega un claro detalle del proceso:

Entendemos el proceso místico como un ascenso que va desde lo orgánico, pasando por lo anímico, a lo espiritual. Esto se traduce en

\footnotetext{
Me refiero a las descripciones de la experiencia mística contenidas en el poema Cántico Espiritual de San Juan de la Cruz, donde el alma pasa por tres estados de ascensión claramente diferenciables para alcanzar la unión con la divinidad. Estas etapas son: Purgativa, Iluminativa y Unitiva, las que dan cuenta de un proceso iniciático donde se trasciende la materia y se orienta la conciencia hacia lo celeste para alcanzar el estado final de "Matrimonio espiritual" planteado por el autor. Véase: San Juan de la Cruz, Cántico espiritual. Santiago de Chile: Ercilla, 1984.
} 
un progresivo aniquilamiento de lo físico para acceder a un puro flujo espiritual. Esta aniquilación de lo físico corresponde a la Purgatio, luego de la cual el flujo espiritual es iluminado (iluminatio). Una vez que el flujo espiritual es iluminado se produce el momento más intenso del proceso: la Unio mística, la unión del alma con Dios (183).

Considerando lo expuesto, la idea de mística de la materia revela un desplazamiento específico de la conciencia para encontrar lo sagrado, que es inverso a la visión impuesta por el pensamiento místico tradicional de autores como Santa Teresa o San Juan de la Cruz, pues en este desplazamiento de la conciencia la atención ya no se orienta hacia lo celeste, sino hacia lo terrestre, es decir, a las materias como portadoras de un elemento sagrado. La mayoría de las interpretaciones teóricas sobre qué es y cómo opera el concepto de mística de la materia surgen de las reflexiones de Gabriela Mistral en torno a la poesía de Pablo Neruda, principalmente, sobre el texto Residencia en la tierra (1935), pues la poeta en algunos escritos se refiere a esta como una poesía orientada a encontrar lo sagrado en lo telúrico, específicamente en dos de sus recados sobre el poeta: "Recado sobre Pablo Neruda" de 1936 y "Pablo Neruda y su mejor reino" de 1943. Mistral indica: "El lector atropellado llamaría a Neruda un antimístico español. Tengamos cuidado con la palabra mística, que sobajeamos demasiado y que nos lleva frecuentemente a juicios primarios. Pudiese ser Neruda un místico de la materia" (Cit. en Scarpa 129).

Para Mistral, Neruda es un poeta que se sumerge en las materias para poder encontrar allí un misterio que conecta con lo sagrado. Y es esta orientación hacia lo profundo lo que aparece como elemento fundamental de una mística de la materia, pues no basta con la contemplación del mundo físico para encontrar la huella de lo divino ${ }^{4}$, en la mística de la materia es necesario romper con la idea de ascensión y volcar la conciencia hacia lo profundo, trascender hacia abajo en un acto de sumersión e ingreso en lo terrestre. Al respecto, las reflexiones de Mistral son claras:

4 La sola contemplación del mundo físico para alcanzar la huella de lo divino se acerca más al concepto de panteísmo, que lleva implícito la noción de un todo sagrado que se reparte en muchos elementos y en varios casos mantiene una orientación ascensional, es decir, se contemplan los elementos del plano físico para ascender hacia su poder creador. Mientras que la mística de la materia no necesariamente implica la noción de un todo sagrado presente en cada elemento de la materia, ya que cada uno puede contener su propio misterio trascendente. Además, su orientación es exclusivamente de ingreso y descenso. 
El poeta, eterno ángel abortado, busca la fiebre para suplirse su elemento original. Ha de haber también unos espíritus angélicos de la profundidad, como quien dice, unos ángeles de caverna o de fondo marino, porque los planos de la frecuentación de Neruda parecen ser más subterráneos que atmosféricos, a pesar de la pasión oceánica del poeta (Cit. en Scarpa 129).

De esta reflexión surge la posibilidad de repensar lo sagrado bajo una nueva perspectiva, pues la conciencia del sujeto no queda exenta de ello al no vincularse con lo celeste, sino más bien, existe la posibilidad de conectar con lo sagrado desde el ingreso en lo profundo de las materias y encontrar el misterio de estos "ángeles de caverna". Con esto, la poeta concluye sobre Neruda que "entonces su poesía se vuelve una especie de mística de la tierra en un vuelo al revés, que no es ascenso sino bajada hacia lo divino subterráneo" (Cit. en Vargas Saavedra 189).

Esta orientación de la conciencia hacia lo profundo de las materias para conectar con lo sagrado contenida en la idea de mística de la materia permite explicar el simbolismo de las plantas y la noción de metáfora vegetal presente en Guitarra negra de Luis Alberto Spinetta, pues se observa en ella una similar aproximación a lo trascendente, donde los hablantes líricos encuentran lo numinoso mediante su conexión con elementos del mundo material como el reino vegetal, los elementos naturales y los animales, especialmente animales y seres mágicos y mitológicos.

Tanto en Guitarra negra como en algunos textos de sus canciones, Spinetta hace alusión a un estado más allá de la materia y de la razón, que se caracteriza por ser un estado primordial, en tanto es origen totalizador de la experiencia del ser y origen anhelado por los hablantes líricos. Éstos encuentran en la naturaleza el acceso a tal dimensión a través de un acto de fusión de su condición humana-finita con una naturaleza vegetal-trascendente proveniente del mundo físico, en la cual el sujeto es transfigurado. Ejemplo de esto se encuentra en el siguiente fragmento del poema "Hombre de la tez ilusoria" perteneciente a Guitarra negra:

¡Las mañanas que toque se partirán en mí!... las lágrimas que venderé por ahí por sus almas se reunirán en el alimento de otros seres con sed y la columna de aire del idilio de los árboles morirá con su prosa de hombre cansado de clamar hombre de la tez ilusoria exhausto ya de clamar a través de sus ramas (58). 
Esta concepción de hombre-árbol presente en la estrofa citada es reiterada en otros textos del poemario, como en el poema que inicia el libro titulado "i", donde el hablante lírico indica: "mis ramas carecen de rezos con los que al flotar se lea el horizonte" (17), y recuerda, además, expresiones de sus canciones como el verso "esta es mi corteza donde el hacha golpeará" de la canción "Barro tal vez" (Kamikaze 1982). Esta situación evidencia cómo se articula la metáfora vegetal que cruza la obra de Spinetta, lo que a su vez permite entender la singular manera del autor de concebir y abordar las problemáticas metafísicas.

En la obra de Spinetta, la relación del sujeto con el reino vegetal, ya sea de manera directa o simbólica, es un rasgo esencial de su concepción espiritual, pues es lo que permite el acceso a lo sagrado y trascendente que algunas veces es cifrado como un origen del ser previo a la materia y otras veces como la trascendencia anhelada del lastre que el sujeto carga. Acceso que es llevado a cabo a través de la vinculación del sujeto con el reino vegetal donde toma forma el concepto de hombre-árbol. Ahora bien, ¿cuál es el lastre que separa al sujeto de esa dimensión sagrada? La lectura y análisis del poemario indican que es su condición humana, en tanto cuerpo, razón y finitud.

Cabe destacar que en la poesía de Spinetta, la materia que es sublimada es solo la que guarda relación con la naturaleza, principalmente, el reino vegetal, pues el tratamiento que en su poesía se le da al cuerpo humano difiere de tal sublimación, ya que éste figura como portador de la finitud y el respectivo asedio del tiempo que los hablantes líricos sufren; ya en sus canciones esto es evidente en versos como: "Si quiero me toco el alma/ pues mi carne ya no es nada" de "Barro tal vez" (Kamikaze 1982). Esta situación resulta paradójica al ser el cuerpo humano un elemento más del mundo material en el cual los hablantes líricos igualmente podrían encontrar lo sagrado; sin embargo, en la obra de Spinetta el cuerpo humano, en tanto materialidad, queda fuera de esta concepción, principalmente por ser el elemento que contiene las limitaciones de la condición humana, situación que muestra la necesidad de los sujetos textuales por transfigurarlo en un cuerpo vegetal. Como indica Jorge Hardmeier: "El cuerpo es un problema. El cuerpo es forma, materia, reunión de átomos. El cuerpo es carne: corrompible, finita, mortal" (Arremete 69).

En Guitarra negra, el cuerpo humano es definido bajo los límites de su materialidad, primeramente como aparato sensitivo: "cuerpo es el sinfín donde experimentamos cada sensación por separado como granos de arena y cada sensación en su totalidad, como arena" (80). Posteriormente, como una proyección del ser desde un estado primordial hacia la materia: "fascinada 
proyección escapada de la muerte [...] de la nada se sugirió su impulso que incumbía a todo lo inexistente" (49). Y, finalmente, como un estado postrero del ser al abordar el plano físico: "yo nacía como un pato salvaje/ pero era sólo consumación de brotes/ era eterno mi corazón/ eterna mi dicha/postrero el cuerpo para criaturarme" (17).

La idea de finitud inherente al cuerpo humano busca ser reemplazada por la existencia plena y atemporal que entrega la condición vegetal-sagrada, de ahí surge la necesidad de la transfiguración al cuerpo vegetal. Situación que también se refleja en canciones como "Barro tal vez" (Kamikaze 1982), donde el sujeto textual busca trascender su humanidad a través del sonido musical y la fusión con la naturaleza mediante el simbolismo del barro:

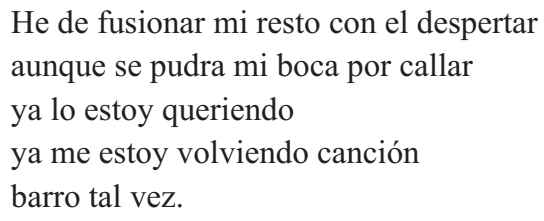

De lo expuesto se puede resumir que la textualización de lo inmaterial y la noción de espiritualidad presentes en el poemario Guitarra negra de Luis Alberto Spinetta, y en gran parte de su música, pueden ser entendidas, principalmente, bajo el concepto de mística de la materia que algunos teóricos definen en función de la poesía de Pablo Neruda y Gabriela Mistral, puesto que en su poesía se observa un ingreso en la materia por parte de los sujetos textuales con el fin de encontrar lo sagrado y numinoso. Destaca en esta situación que Spinetta elabora una noción de espiritualidad ligada a la materia pero de forma selectiva, puesto que solo la naturaleza es portadora del acceso a lo sagrado. El cuerpo como materialidad es relegado a un estado de finitud que los hablantes rechazan y es desplazado de la "materia sagrada" que lleva a lo trascendente. Además, si bien en la poesía de Spinetta toda la naturaleza es capaz de revelar lo sagrado, el simbolismo de las plantas es el rasgo distintivo de la sublimación del ser en su escritura, fenómeno que también está presente en su música. Esto encuentra su máxima expresión en la fusión del sujeto textual con la naturaleza vegetal del árbol como símbolo de la existencia plena.

Cabe destacar, además, que si bien la conexión entre la materia y lo sagrado es la característica esencial y dominante en la concepción espiritual presente en Guitarra negra, esta no es exclusiva, pues también en el poemario 
se encuentran algunas desviaciones hacia concepciones propias de la mística tradicional que se caracteriza por la figura ascensional, como la idea panteísta de que a través de la materia se asciende a lo sagrado, donde la figura del ser creador está expresada y contenido en su creación, "es un momento para pensar en Dios/ (comprender que somos parte de una/ totalidad que nos contiene" (18), indica el poema "i". Además, en algunos textos se encuentran reflexiones donde lo espiritual tiene primacía sobre la materia, como en el poema "iv" que indica:

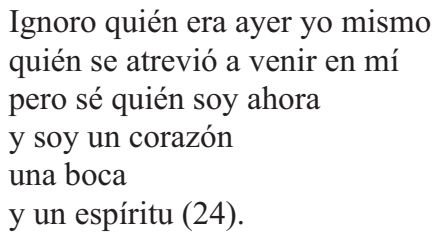

Estos versos plantean una reflexión donde el ser esencial del hablante lírico se encuentra en lo inmaterial. O las figuraciones de la luz como característica de lo sagrado, "es la hora en la que toda luz se desespera por brillar/ y toda mi sombra se estremece al sentirse sabida" (18), que puede vincularse con la asociación de la sombra con el cuerpo y las pasiones presente en la mística tradicional, sombra que se busca reconocer con el fin de trascenderla hacia la luz del espíritu. Incluso hay textos que recuerdan los planteamientos de la tradición cristiana: "mas le oigo decir innumerables veces:/ 'yo soy de otro reino/ venid a mí/ venid a mí' (19), a pesar de las claras negaciones al respecto: "yo ignoraba a los profetas" (17).

Sin embargo, en Guitarra negra estas concepciones no se oponen sino que conviven con la noción de espiritualidad vinculada al plano material que en el poemario adquiere un rol predominante mediante las ideas de metáfora vegetal y mística de la materia. Dominancia que queda clara al considerar que para Spinetta prima la conexión de los sujetos textuales con lo sagrado mediante el vínculo y acceso a la materia, principalmente la naturaleza, pues incluso la figura de Dios en el poemario tiene su equivalente vegetal en una flor, sus pétalos y su tallo, como se indica en el siguiente fragmento del poema "Voz de dios":

Oigo su gemido de papiro

de suceso que dice

de inabarcable reposo

de pensamiento 


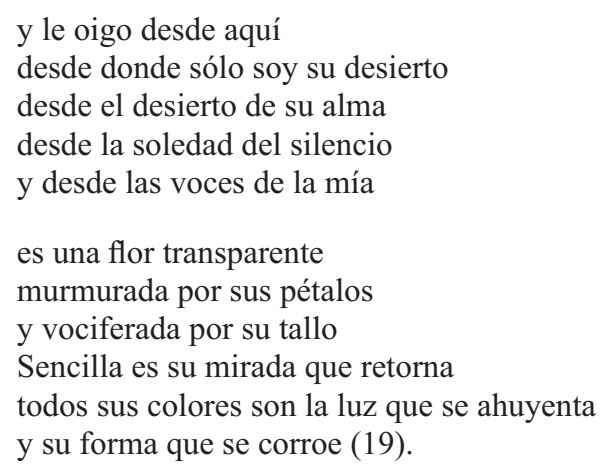

Esta problemática metafísica presente en la obra de Spinetta pareciera indicar la necesidad de reestablecer algunas formas de comprensión de la realidad más allá de lo racional, situación que conecta con el concepto de "postontología" que el alemán Wolfgang Janke (1995) propone en sus reflexiones acerca de la postmodernidad. Janke analiza el estado actual de la metafísica y critica el pensamiento que en la modernidad la desplazó. Dicho pensamiento se compone de dos vertientes claramente identificables: por una parte, el desarrollo y auge del positivismo, y la instalación de la idea de verdad en el conocimiento observable y comprobable, propio de la ciencia y la tecnología, y, por otra parte, el surgimiento del nihilismo, con todo el descreimiento que implica de los grandes metarrelatos mítico-sagrados que explicaban la realidad.

Desde esta crítica, el autor plantea una interrogante fundamental: “¿Qué sucedería si los discursos religioso-mitológicos y filosófico-metafísico fuesen exposiciones del mundo de igual linaje que la exploración científica, porque así se ocupen de intenciones cognoscitivas y verdades diversas, éstas son igualmente esenciales que las de las ciencias?" (25-26). En función de esta interrogante, el autor propone el concepto de postontología, que se refiere a un sustrato metafísico renovado que supere los límites del positivismo y el nihilismo y la exacerbada conciencia racionalista que determina la actual interpretación y legitimación de la realidad. Esta nueva ontología postmoderna implicaría retomar el pensamiento mítico, recuperar el valor de lo sagrado como factor determinante del quehacer humano y reestablecer el valor estético-poético de sus manifestaciones.

Estos planteamientos encuentran correspondencia en la poesía de Luis Alberto Spinetta, en tanto ambos autores se aproximan a una revaloración de lo sagrado y los cuestionamientos metafísicos como verdades posibles 
para explicar la realidad, Janke desde la reflexión teórica y Spinetta desde el ejercicio estético.

En Guitarra negra es posible observar un intento por recuperar un sustrato metafísico que le dé sentido a la existencia de los sujetos textuales, tal como describe Janke, situación que ocurre a través de la vinculación de los hablantes líricos con la revelación de lo sagrado que surge de la naturaleza. Esto se logra mediante la orientación de la conciencia de los hablantes hacia las materias como portadoras del elemento que permite la trascendencia de sus existencias limitadas por su finitud. En este contexto, Spinetta retoma el pensamiento mítico-sagrado señalado por Janke, pues en su obra, además de la importancia de lo espiritual y las reflexiones metafísicas ya mencionadas, se encuentra la mención específica a seres mitológicos y sobrenaturales, tales como ave fénix, duendes y gnomos, situación que viene a completar la importancia que lo mítico tiene en su obra como acceso a nuevas realidades.

A su vez, Spinetta intenta reestablecer el valor de la palabra poética como portadora de un misterio que excede los límites de la razón y que se vincula con sus ideas sobre lo sagrado. El siguiente poema titulado "Lapsos" ilustra esta situación:

Haber descifrado la madeja

haber inquietado estos sentimientos

prolongado estos lapsos

inundado estas ideas y estas palabras

es sólo haber pasado por un aire

sin reflejos siquiera del código del tiempo

todo este espacio fue eterno

¿verdad antigua poesía

anterior lucha

lejana canción

silueta de los labios del último verso?...

todo este tiempo fueron humores

una hilera de cadencias

una cuchillada retirada del cuerpo

una herida vaciada

un leve sueño

y el país entre este signo

y aquél último

(el último rincón mirado 
la recóndita falencia representada)

es el país de la huella

¡hibridez de un territorio!

aprisionamiento entre aquella y esta "carne"

intertapiado de rumores

entre eslabones y paredes

de la única poesía

poesía que sangra

$\mathrm{y}$ al detenerse abre la frontera

y sopla los papeles vacíos

dice denuncias de ese absoluto dios poético

dios de la miserable porción de infinito entre estas palabras

y las que vendrán (88).

Como se aprecia en el poema, existiría un ejercicio de lenguaje que implica descifrarlo, trabajar con ideas y palabras, incluso implica el involucramiento de la naturaleza emotiva del hablante, es un flujo comunicativo, "estas palabras y las que vendrán”. Sin embargo, para el sujeto esta comunicación supone un ejercicio vago de la vastedad que implicaría el concepto de "única poesía", poesía más abarcadora que un ejercicio de lenguaje en la que subyace una visión trascendentalista del arte. Esta noción de poesía única y trascendente está en sintonía, además, con las lecturas de poetas decimonónicos que en las biografías citadas el músico declara en relación con las ideas de inspiración poética y genio creador, situación que permite rastrear en su escritura ciertos rasgos neorrománticos que conviven con matices surrealistas, como fue mencionado al comienzo de este estudio. Se renueva entonces en el poema citado la visión del arte a través de su sublimación en esta "única poesía", pero es toda la obra de Luis Alberto Spinetta la que intenta recuperar el pensamiento mítico-sagrado y el pensamiento estético-poético propios de la postontología propuesta por Janke, ya que las temáticas de sus canciones no están exentas de una intensa carga de espiritualidad y sublimación del arte "iQuién resistirá!/ cuando el arte ataque"5. Por ende, no es de extrañar que Guitarra negra culmine con la mención a un "verdadero poema" que

Estos versos corresponden a la canción "Cuando el arte ataque", contenida en el disco La la la, de 1986, grabado junto al músico rosarino Fito Páez. 
estaría más allá de la poesía convencional: "este verdadero poema/ no ha sido resuelto aún/ pero quiere vivir bajo su forma/ aquí/ como sea" (104).

\section{CONCLUSIONES}

Para finalizar se puede indicar que en la obra creativa de Luis Alberto Spinetta se observan algunas recurrencias temáticas que vinculan su práctica poética con su práctica musical; sin embargo, como revela el estudio del poemario Guitarra negra, su poesía puede ser estudiada como una obra literaria autónoma respecto de su música, pues no parece constituir una extensión de esta última, sino por el contrario, las ideas e influencias literarias presentes en su poesía pueden ser consideradas como un sustrato en el cual sus letras de canciones encuentran mayor riqueza textual.

En función de esta autonomía se han planteado reflexiones en torno a su posible ubicación en la tradición literaria argentina mediante algunas propuestas de generaciones y periodizaciones. Esto, con el fin de contextualizar las influencias literarias que el análisis de su poemario ha revelado, específicamente, las ideas y procedimientos que se vinculan al Romanticismo y al surrealismo.

Más allá de cualquier vinculación de la poesía de Spinetta con movimientos y corrientes literarias, Guitarra negra muestra algunas claves específicas para su análisis, principalmente una particular noción de espiritualidad y la revelación de lo sagrado como experiencia fundamental en la existencia de los hablantes líricos. Esta situación se ve reflejada en los conceptos de metáfora vegetal y mística de la materia que se han aplicado a su poesía, que dan cuenta de la especial configuración de lo sagrado en el poemario. Para Spinetta, las materias son portadoras de un misterio trascendente, y la naturaleza el principal conector entre este misterio y los sujetos textuales; de ahí la recurrencia de los hablantes que trascienden su existencia humana vinculándose a elementos como el barro o los árboles, pues estos aparecen en la obra poética del argentino como símbolos de la sublimación de la existencia.

Por último, se puede indicar que en la poesía de Spinetta se observa un intento por recuperar el valor de las manifestaciones de lo sagrado y de lo artístico, situación que conecta con el concepto de postontología propuesto por Wolfgang Janke, que se basa en el restablecimiento de la importancia del pensamiento mítico-sagrado y del pensamiento estético-poético. Esta situación permite instalar a la poesía de Spinetta en problemáticas culturales 
actuales, como la intermedialidad y los estudios interartísticos que vinculen literatura y música, el estudio de los vínculos entre alta cultura y cultura de masas, o el rol de la espiritualidad y lo sagrado en la poesía latinoamericana contemporánea, lo que da cuenta de su valor y de su vigencia.

\section{BIBLIOGRAFÍA}

Blanchot, Maurice. El espacio literario. Buenos Aires: Editorial Paidós, 1969.

De la Cruz, San Juan. Cántico espiritual. Santiago de Chile: Ercilla, 1984.

Diez, Juan Carlos. Martropía. Conversaciones con Spinetta. 2006. Buenos Aires: Aguilar, 2012. $1^{\text {a }}$ edición Electrónica. Libresque, 2012. Recuperado de: $<$ http://es.slideshare.net/ pdfshares/martropia-conversaciones-con-spinetta $>$ Abril de 2017.

Ferrater Mora, José. Diccionario de Filosofía. Buenos Aires: Ed. Sudamericana, 1964.

Garrido, Marcelo. "Seis ensayos sobre el espacio poético y el espacio reflexivo desde la tradición poética chilena (Raúl Barrientos, Enrique Lihn, Gabriela Mistral) (Gianni Vattimo, Maurice Blanchot, María Zambrano)”. Tesis Doctoral. Universidad de Concepción, 2010.

Gasparini, Sandra. "Sandra Gasparini habla del libro Iniciado del alba a cinco años del fallecimiento de Luis Alberto Spinetta". Entrevista en el programa radial Verano Fatal, a cargo de Cintia Rodil y Jorge Pérez. Radio Universidad Nacional de La Plata. 08 de febrero de 2017. La Plata: Repositorio Institucional de la Universidad Nacional de La Plata, 2017. Recuperado de: <http://sedici.unlp.edu.ar/handle/10915/58656> Julio de 2017. Audio mp3.

"Guitarra negra, palabras luminosas". Iniciado del alba. Seis ensayos y un epílogo sobre Luis Alberto Spinetta. Comp. Sandra Gasparini. Buenos Aires: Autores de Argentina, 2015 .

Ghiano, Juan Carlos. Constantes de la literatura argentina. Buenos Aires: Raigal, 1953.

Hardmeier, Jorge. “Arremete viajero". Boca de sapo $\mathrm{N}^{\circ}$ 12. Buenos Aires: Boca de sapo, 2012. 66-71. Recuperado de:. <http://www.bocadesapo.com.ar/biblioteca/bds/BdS12. pdf $>$ Julio de 2017.

"Una lectura de Guitarra negra/Luis Alberto Spinetta: Arremete Viajero" weblog de Biblioteca AUPA. 2012. Web. Julio de 2017.

$<$ http://paraunregalodeboda.blogspot.cl/2012/02/jorge-hardmeier-un-articulo-para-la.html $>$

Iniesta, Amalia. "Reflexiones en torno de las posibilidades de una historia integral de la literatura argentina". La periodización de la literatura argentina. Problemas, criterios, autores y textos. Tomo II. Actas del IV Congreso Nacional de Literatura Argentina, 2327 de noviembre de 1987. Mendoza: Universidad Nacional de Cuyo, 1989. 191-200.

Janke, Wolfgang. Mito y poesía en la crisis Modernidad posmodernidad. Buenos Aires: La Marca, 1995.

Minniti, Ana, Marisa Coria y Silvina Siliano. "Las revistas literarias rosarinas (1965-1976)". La periodización de la literatura argentina. Problemas, criterios, autores y textos. Tomo 
III. Actas del IV Congreso Nacional de Literatura Argentina, 23-27 de noviembre de 1987. Mendoza: Universidad Nacional de Cuyo, 1989. 9-27.

Monteleone, Jorge. "Rock y Poesía: La Noche de Marsella". Everba 1, summer (2002). Recuperado de: <http://eter.org/everba/summer02/noche_jorge.htm> Abril de 2017.

"Figuras de la pasión rocker. Ensayo sobre rock argentino". Everba 1 summer (2002).

Recuperado de: <http://eter.org/everba/summer02/figuras_jorge.htm>. Abril de 2017.

"Spinetta/Artaud. Verano del setenta y tres". Controversias de lo moderno: la secularización en la historia cultural latinoamericana. Ed. Enrique Foffani. Buenos Aires: Katatay, 2010. 185-209. Recuperado de: $<$ http://documents.mx/documents/spinetta-artaudverano-del-setenta-y-tres-por-jorge-monteleone1doc.html>. Abril de 2017.

Otto, Rudolf. Lo santo. Madrid: Revista de Occidente, 1965.

Pio del Corro, Gaspar. "Dos vías de periodización de nuestra literatura”. La periodización de la literatura argentina. Problemas, criterios, autores y textos. Tomo I. Actas del IV Congreso Nacional de Literatura Argentina, 23-27 de noviembre de 1987. Mendoza: Universidad Nacional de Cuyo, 1989. 191- 202.

Poblete, Kira. "El Surrealismo argentino y su praxis". La periodización de la literatura argentina. Problemas, criterios, autores y textos. Tomo III. Actas del IV Congreso Nacional de Literatura Argentina, 23-27 de noviembre de 1987. Mendoza: Universidad Nacional de Cuyo, 1989. 93-104.

Porrúa, Ana María. "Notas sobre la poética del 60". La periodización de la literatura argentina. Problemas, criterios, autores y textos. Tomo III. Actas del IV Congreso Nacional de Literatura Argentina, 23-27 de noviembre de 1987. Mendoza: Universidad Nacional de Cuyo, 1989. 105-117.

Rubio, Cecilia. "Las figuras de la trascendencia en la vanguardia chilena: arte hermético, arte espiritual". Crítica y creatividad. Acercamientos a la literatura chilena y latinoamericana. Ed. Gilberto Triviños y Dieter Oelker. Concepción: Ediciones Universidad de Concepción, 2007. 311-333.

Scarpa, Roque Esteban, comp. Gabriela piensa en.... Gabriela Mistral. Santiago de Chile: Andrés Bello, 1978.

Spinetta, Luis Alberto. Guitarra negra. 1978. Buenos Aires: La Marca, 2008.

La la la. Grabado junto al músico Fito Páez. EMI Argentina, 1986. CD. Kamikaze. BMG Argentina, 1982. CD.

Vargas Saavedra, Luis, comp. Recados para hoy y mañana. (Textos inéditos). Gabriela Mistral, Tomo I. Santiago de Chile: Ed. Sudamericana, 1999.

Vásquez, Virginia y Alejandro Kuperman. "Revistas literarias del 60: un aporte para la periodización de la literatura argentina”. La periodización de la literatura argentina. Problemas, criterios, autores y textos. Tomo II. Actas del IV Congreso Nacional de Literatura Argentina, 23-27 de noviembre de 1987. Mendoza: Universidad Nacional de Cuyo, 1989. 201- 217. 